

\title{
Compliance of NHS dental practice websites in Wales before and after the introduction of the GDC document 'Principles of Ethical Advertising'
}

\author{
M.L. Budd ${ }^{1}$, M. Davies ${ }^{2}$, R. Dewhurst ${ }^{3}$, P.A. Atkin $*^{4}$
}

\section{Qualifications:}

1 BDS MFDS RCSEd

2 BDS

3 BDS

4 MBBS MSc FDS RCS Eng FDS(O Med) RCPS Glasg FHEA

\section{Addresses:}

1 Dental Core Trainee, School of Dentistry, Cardiff University, Heath Park, Cardiff, CF14 4XY

2 Dental Practitioner, St Ives, Cornwall, UK

3 Dental Practitioner, South West Rocks, New South Wales, Australia

4 Consultant and Honorary Senior Lecturer, School of Dentistry, Cardiff University, Heath Park, Cardiff, CF14 4XY

* Correspondence to Dr Phil Atkin. email: atkinpa@cardiff.ac.uk

Objectives To evaluate the compliance of NHS dental practice websites in Wales, UK, with the 2012 GDC document Principles of Ethical Advertising, before its introduction (2011) and again after its introduction (2014)

Methods All practices in Wales with an NHS contract and dental practice website were identified. The content of the website was evaluated to determine if it complied with the principles outlined in the 2012 GDC document Principles of Ethical Advertising

Results $25 \%$ of the 446 practices sampled in 2011 had a website, compared to $44 \%$ of the 436 practices sampled in 2014. The principles best complied with were; displaying the name, geographic address, and telephone number of the practice ( $100 \%$ for both years). None of the websites compared the qualifications or skills of its practitioners to others, therefore $100 \%$ complied with this principle. Displaying team members' professional qualification and country from which this is obtained was fairly well represented; $92 \%$ and 61\% respectively in 2014; an improvement from only 50\% and 49\% respectively in 2011. Principles worst complied with were displaying the GDC's address (3\% 2011; 9\% 2014) or link to the GDC website $(11 \% 2011 ; 7 \% 2014)$ and details of the practice complaints procedure (1\% 2011; 5\% 2014). Overall, no practice complied with all of the compulsory principles

Conclusion In both 2011 and 2014 no practice website was compliant with all the principles outlined in the 2012 GDC document Principles of Ethical Advertising. Reflecting results from previous studies, this study showed that compliance is slowly improving, yet over 4 years after the introduction of the mandatory principles, still no practice website is $100 \%$ compliant 


\section{INTRODUCTION}

The UK General Dental Council (GDC) first relaxed its absolute restriction on dentists advertising in 1985, followed by more extensive freedom to advertise in 1988. Guidance on advertising is present in the GDC Standards documents, including the most current Standards for the Dental Team. ${ }^{1}$

General advertising regulations are written by the Broadcast Committee of Advertising Practice and the Committee of Advertising Practice, and enforced by the Advertising Standards Authority (ASA), with the aim of ensuring that all adverts are legal, decent, honest, and truthful.

The content on dental practice websites must conform to the Code of Conduct for Dentists for Electronic Commerce in the EU, ${ }^{2}$ and the Code of Ethics for Dentists in the EU for Electronic Commerce. ${ }^{3}$ In 2011, the GDC produced the document Principles of Ethical Advertising based on these EU guidelines. ${ }^{4}$ This document was recommended to council for approval in 2011, to initially be released as a guidance sheet, before being published with the remaining standards as a whole, following their review in 2012.

With the advent of smartphones, sourcing information from the internet is more common than ever, and increasingly patients are turning to the World Wide Web to obtain information on dental practices, ${ }^{5,6}$ including finding a new dental provider, and to research their dental condition. ${ }^{7}$ Having a practice website that can be identified via an internet search is therefore desirable, and is becoming standard business practice for dentists, ${ }^{8-11}$ being described as "a key part in the success of a modern dental practice". ${ }^{12}$ Despite this, studies have shown that not all providers of dentistry in the UK have a practice website, and even when they do, compliance with advertising rules and regulations is poor.

\section{BACKGROUND}

In 2005, Addy et al. ${ }^{9}$ found that not all practices were compliant with EU advertising regulations, suggesting this was due to lack of practitioners' awareness of the regulations, and so, recommended that the GDC should do more to make practitioners aware of the relevant guidelines.

Similarly, in 2011, Nichols and Hassall ${ }^{13}$ found overall compliance with advertising regulations to be poor; of a random sample of 150 UK dental practices, only $35 \%$ had a website, none of which complied with all advertising regulations. Information most frequently present was the name of the practice (96\%), telephone number $(100 \%)$ and address $(98 \%)$. Poorly represented information was a link to the GDC website $(19 \%)$, date the website was last updated (8\%) and GDC contact details (4\%).

In 2014, Raimundo \& Robinson ${ }^{12}$ and Parekh \& Gill ${ }^{6}$ found that practices were still not complying with all rules and regulations. Links to GDC website were again poorly represented (34\%, 50\% respectively) and only a very small number made patients aware of their practice complaints procedure ( $26 \%, 7 \%$ respectively), despite these being compulsory according to the GDC. 
This study was conducted to investigate the compliance of NHS dental practice websites in Wales with mandatory GDC rules on advertising, before and after their introduction in March 2012, and to allow tentative comparisons to similar studies of dental practice websites in the UK.

\section{METHODS}

All practices which offer NHS dentistry in Wales are registered on the NHS Wales Online Directory (www.wales.nhs.uk/ourservices/directory). In 2011 and again in 2014, this directory was accessed. At that time, practices with a current website were identified (prospective audit) via searching the UK online Yellow Pages directory at www.yell.com. If the practice website could not be identified from www.yell.com, the practice name, city and postcode was entered into a search on www.google.co.uk and the first two pages of search results reviewed. All identified practice websites were visited, and all pages scrutinised against the principles listed in the 2012 GDC document Principles of Ethical Advertising (Fig. $1)$.

Data collection was carried out by different researchers in 2011 and 2014 with no comparisons made between these individuals, however the method adopted was simple and identical, so there is no reason why bias should be present. The UK online Yellow Pages directory was used as the initial search tool as its database allows browsing a list of dentists in Wales (which was cross referenced to the NHS Wales Online Directory), with a direct hyperlink to the practice website. This was deemed a faster method than searching each practice individually by entering information into www.google.co.uk, allowing a significant number of websites to be quickly identified, before having to search by relevant information typed into Google. The authors recognise that because businesses have to actively register to appear on www.yell.com, not all NHS dental practices in Wales would have been identified by this database. This is therefore why Google was used secondarily in each search, to try and avoid missing any practices.

\footnotetext{
In line with European Guidance, for all dental professionals providing dental care mentioned on the site the following information must be displayed:

i) their professional qualification and the country from which that qualification is derived; and

ii) their GDC registration number.

Dental practice websites must display the following information:

i) the name and geographic address at which the dental service is established;

ii) contact details of the dental service, including e-mail address and telephone number;

iii) the GDC's address and other contact details, or a link to the GDC website;

iv) details of the practice's complaints procedure and information of who patients may contact if they are not satisfied with the response (namely the relevant NHS body for NHS treatment and the Dental Complaints Service for private treatment) and

v) the date the website was last updated.
}

Fig.1 Website advertising rules in GDC Principles of Ethical Advertising 


\section{RESULTS}

Only $25 \%$ of the 446 practices sampled in 2011 had a website, increasing in 2014 to $44 \%$ of the 436 practices sampled.

It can be seen from Table 1 that providing basic information about the practice is better complied with than other principles outlined by the GDC. All practices with websites displayed the practice name, address and phone number, as would be expected from any business website. Similarly, none of the practices compared the qualifications or skills of its practitioners to others, therefore $100 \%$ fulfilled this requirement. Displaying the professional qualification of the practitioner improved following introduction of the GDC rules, $(50 \% 2011 ; 92 \%$ 2014) but this was not always supplemented with the country in which this qualification had been awarded (49\% 2011; 61\% 2014). As expected, more websites provided email addresses in 2014 (85\%) than 2011 (66\%) but it is surprising that still only $85 \%$ of practices are choosing to allow patients to contact them in this way, considering the increasing use of internet and email communication. Provision of an email address was also one of the principles most well represented when investigated by Raimundo \& Robinson, ${ }^{12}$ however this was not reflected in the current study. Interestingly, compliance with displaying practitioners' GDC registration number was good in 2011 (84\%) but dropped to only $63 \%$ in 2014 , despite being a mandatory principle. Poorly represented principles were those pertaining to contact details for the GDC. In 2011, only $3 \%$ of practice websites displayed the GDC address, improving only marginally to 9\% in 2014. In 2011 only $11 \%$ displayed a link to the GDC website, falling to $7 \%$ in 2014 . The principle that was most poorly complied with concerned complaints procedures. In 2011, only 1 website displayed details of its practice complaints procedure and none of the websites gave details of the NHS complaints procedure. Compliance with both principles has improved since the introduction of the guideline, but overall is still very poor; only $5 \%$ displayed practice complaints procedure and 10\% mentioned the NHS complaints procedure in 2014.

GDC rules and regulations state that information in adverts must be current, and website information must be updated regularly to accurately reflect the practice personnel and services offered. Despite this, around half of the practice websites did not state when the website was last updated (52\% in 2011; $47 \%$ in 2014).

Overall, adherence to the GDC document Principles of Ethical Advertising improved between 2011 and 2014 following its introduction in 2012, but it is difficult to say if the improvement is as a direct result of the document being published. However, none of the practice websites were fully compliant with the document.

\begin{tabular}{|l|l|c|}
\hline \multicolumn{2}{|l|}{ Table 1- Results } & \multicolumn{1}{|c|}{2011} \\
\hline Section 1 - Presence of practice website & & \\
\hline Does the dental practice have a website? & $110(25 \%)$ & $193(44 \%)$ \\
\hline $\begin{array}{l}\text { Section 2 - Compliance with GDC Ethical Advertising } \\
\text { principles. Of those practices with websites, does the } \\
\text { website display the following compulsory information? }\end{array}$ & & \\
\hline Practice name & $110(100 \%)$ & $193(100 \%)$ \\
\hline Practice address & $110(100 \%)$ & $193(100 \%)$ \\
\hline Practice phone number & $110(100 \%)$ & $193(100 \%)$ \\
\hline
\end{tabular}




\begin{tabular}{|l|l|l|}
\hline Practice email address & $73(66 \%)$ & $164(85 \%)$ \\
\hline Practitioners' professional qualification & $55(50 \%)$ & $178(92 \%)$ \\
\hline Country from which the qualification is derived & $54(49 \%)$ & $118(61 \%)$ \\
\hline GDC registration number of each practitioner & $92(84 \%)$ & $122(63 \%)$ \\
\hline GDC's address & $3(3 \%)$ & $17(9 \%)$ \\
\hline A link to the GDC website & $12(11 \%)$ & $14(7 \%)$ \\
\hline Details of the practice complaints procedure & $1(1 \%)$ & $10(5 \%)$ \\
\hline Details of the NHS complaints service & $0(0 \%)$ & $19(10 \%)$ \\
\hline The date the website was last updated & $57(52 \%)$ & $91(47 \%)$ \\
\hline Not to compare the skills or qualification of practitioners & $110(100 \%)$ & $193(100 \%)$ \\
\hline
\end{tabular}

\section{DISCUSSION}

As found by other authors, ${ }^{5,13}$ the number of dental practices with a website continues to grow. This is not surprising, given the increased use of the internet by patients and increased competition amongst dental practices, however, what is surprising is that over half of the NHS practices in Wales still do not have a website. It is the authors opinion that a practice is more likely to have a website if they provide private dentistry, perhaps because they have more revenue to fund a website, but also because advertising of private services is a priority - patients looking for private services have total choice as to where they attend, so advertising on a website is an important way for practices to stand out from competitors and gain 'customers'. It would therefore be interesting to investigate if those practices providing private and NHS services are more likely to have a website than those solely providing NHS dentistry.

The results of this recent study in Wales reflect findings in the UK as a whole. Since 2005, the most poorly represented principles were those relating to information on the governing body of dentistry- the GDC, and information for patients who are dissatisfied and want to complain. ${ }^{6,9,12,13}$ Unfortunately, in keeping with these findings, the current study shows, this is still the case. Failing to display ones GDC registration number is unlikely to greatly impact patients, as if required, this can be obtained on the GDC website by simply searching the practitioner's name. However, it can be reassuring for patients to know immediately that the practitioner is registered with the required regulatory body, and therefore in its absence could negatively influence a patient's choice of practice or dentist. Therefore, by failing to display this simple piece of information, a dentist could be negatively impacting themselves. Regarding complaints procedures and GDC address or website link, perhaps practices are concerned that as a result of displaying this information on their website more patients may complain. The reality is however that practices must display their complaints procedure where patients can see it anyway (in line with Standards for the Dental Team), ${ }^{1}$ and it is thought that displaying information on how to complain can help resolve complaints and prevent them from escalating. ${ }^{6}$

As several studies have confirmed that no practice website has ever been, nor is currently fully compliant with Principles of Ethical Advertising it would be beneficial to find out why this is the case, as the current lack of compliance is unacceptable, especially when the requirements are simple, and editing a website to comply with the guideline is, in the majority of cases, an easy task. The authors are in agreement with Addy et al. ${ }^{9}$ that perhaps not many practitioners or web design companies are aware of the GDC advertising rules and regulations, and as such are unknowingly non-compliant. If this is confirmed to be the case, then a strategy to target this can be devised. Furthermore, increasing awareness that each 
registrant is responsible for the content of any material which contains their name may make them more likely to check the correctness of the information on their practice website. The GDC's guidance on ethical advertising is mentioned in Standards for the Dental Team $^{1}$ - a document that all practitioners should be familiar with, however it is likely that the GDC could do more to make registrants aware of the rules governing advertising, especially as the number of practice websites grows, and as such, the risk of breaching the rules increases.

The GDC takes non-compliance with guidelines seriously, especially where information could mislead patients. The findings of the current study perhaps reflect under-informing, rather than mis-informing, yet this is still not acceptable. The ASA can enforce penalties for breach of its regulations, and indeed a case involving a dentist was upheld in $2013,{ }^{14}$ however this was due to website information being considered misleading, rather than lacking.

The authors are unaware of any other GDC guideline to which not a single practice in the UK complies, yet there are no known cases where the GDC has imposed a penalty for failing to comply with Principles of Ethical Advertising, and it is not known why this is the case.

\section{CONCLUSION}

This study looked at NHS practice websites in Wales only, however there is no reason findings should not be generalisable to the rest of the UK. The study helped to highlight that practices are still failing to comply with the GDC's compulsory rules on advertising, despite their introduction over 4 years ago. Overall, studies have shown growth in the number of practices with a website, and a small improvement in compliance with GDC advertising rules, however it is still unclear why $100 \%$ of practices fail to comply with all the compulsory requirements. Dental registrants are urged to check the content of their practice website against the GDC document and ensure all necessary information is present, before penalties for non-compliance occur, and perhaps the GDC could do more to ensure practitioners and practice websites comply with the compulsory principles outlined by them.

\section{REFERENCES}

1. General Dental Council. Standards for the dental team. 2013. Online information available at https://www.gdc-uk.org/Dentalprofessionals/Standards/Pages/standards.aspx (accessed January 2016).

2. HM Government. The electronic commerce (EC directive) regulations. 2002. Online information available at http://www.legislation.gov.uk/uksi/2002/2013/contents/made (accessed December 2015).

3. The Council of European Dentists. Code of ethics for dentists in the European Union. 2007. Online information available at http://www.eudental.eu/ced-code-of-ethics.html (accessed December 2015).

4. General Dental Council. Principles of ethical advertising. 2012. Online information available at https://www.gdc-uk.org/Dentalprofessionals/Standards/Pages/Ethical-advertising.aspx (accessed January 2016).

5. Chestnutt I G, Reynolds K. Perceptions of how the internet has impacted on dentistry. Br Dent J 2006; 200: 161-165.

6. Parekh J, Gill D S. The quality of orthodontic practice websites. Br Dent J 2014; 216 : E21.

7. Ní Riordain R, McCreary C. Dental patients' use of the internet. Br Dent J 2009; 207: 583-586.

8. Joyal F. Making people want dentistry. J Calif Dent Assoc 1998; 26: 502-505. 
9. Addy L D, Uberoi J, Dubal R K, McAndrew R. Does your practice website need updating? Br Dent J 2005; 198: 259-260.

10. British Dental Association. Marketing. 2012. Online information available at https://www.bda.org/dentists/advice/ba (accessed January 2016).

11. Clow K E, Stevens R E, McConkey C, Loudon D L. Attitudes of dentists and dental patients towards advertising. Health Mark Q 2007; 24: 23-34.

12. Raimundo $\mathrm{H}$, Robinson P K. An audit of implant practice websites: content and regulatory compliance. Br Dent J 2014; 217: 673-677.

13. Nichols LC, Hassall D. Quality and content of dental practice websites. Br Dent J 2011; 210: E11.

14. Advertising Standards Authority. ASA Adjudication on Woodvale Clinic. 2013. Online information available at https://www.asa.org.uk/Rulings/\%20Adjudications/2013/5/WoodvaleClinic/\%20SHP_ADJ_206574.aspx\#.VulGvMf8E7d (accessed March 2016) 